\title{
EDUCAÇÃO SOCIAL E ESCOLAR E O DIREITO À EDUCAÇÁO NA MEDIDA SOCIOEDUCATIVA
}

\author{
SOCIAL AND SCHOOL EDUCATION AND THE RIGHT \\ TO EDUCATION AS A SOCIO-EDUCATIONAL MEASURE
}

\author{
Maria Nilvane Zanella \\ Doutora em Educação pela Universidade Estadual de Maringá, Brasil (2018) \\ Professora Associada da Universidade Federal do Amazonas (UFAM). \\ Amazonas - AM - Brasil \\ ORCID: http://orcid.org/0000-0002-3420-2714 \\ nilvane@gmail.com
}

Angela Mara de Barros Lara

Pós-Doutorado em Educaçáo na Universidade Federal de Santa Catarina. Professora Associada da Universidade Estadual de Maringá. Paraná - PR - Brasil ORCID: http://orcid.org/0000-0001-8799-8413

angelalara@ymail.com

Belmiro Gil Cabrito

Doutorado em Política e Sistema Educativo pela Universidade de Lisboa. Professor Associado aposentado IE-UL. Portugal. ORCID: https://orcid.org/0000-0003-0420-5639

b.cabrito@ie.ulisboa.pt

\begin{abstract}
Resumo: O artigo é produto de reflexôes sobre a articulação entre educação social e educaçáo escolar para viabilizar o retorno à escola de adolescentes que cumpriram medidas socioeducativas de internação e semiliberdade ou em cumprimento de medidas em meio aberto. Apresenta, inicialmente, reflexões sobre os fundamentos da educação social como forma de evidenciar a função da educação escolar, problematizando questôes - atrasos, violências domésticas e comunitárias, dentre outras - que têm contribuído para que a escola e seus profissionais não consigam realizar a sua função social, que é ensinar. Além disso, evidencia as confusóes teóricas sobre o papel de cuidar e educar, discutindo como os problemas disciplinares interferem na organização das escolas públicas e, consequentemente, no processo ensino-aprendizagem. Para tanto, avançamos para proposta de modo de operar a rede de proteção socioassistencial e de saúde para garantir a inserção e a permanência escolar de adolescentes durante ou depois do cumprimento da medida socioeducativa, incluindo uma lista de sugestóes de articulação dos programas de atendimento socioeducativo com as instituiçôes escolares. $\mathrm{O}$ estudo realiza uma pesquisa bibliográfica e documental para a análise de políticas educacionais.
\end{abstract}

Palavras-chave: Educação Escolar. Educação Social. Medida Socioeducativa. Adolescente em conflito com a lei. Indisciplina escolar. 
Aвstract: The article is a reflection about the articulation between social education and scholar education to enable the return to school of teenagers who completed socioeducation measures of hospitalization or semi-freedom or in compliance with measures in open regime. It presents, initially, reflection on the foundations of social education as a way to highlight the function of scholar education, problematizing issues - delays, domestic and community violence, among others - that have contributed to the school and its professionals failing to fulfill their social function, which is to teach. Furthermore, it shows the theoretical confusions about the school role of caring and educating, discussing how the disciplinary problems interfere in public schools organizations and, consequently, in the teaching-learning process. Therefore, we propose a way of operating the socio-health and health protection network, to ensure the insertion and stay of adolescents during or after the fulfillment of the socio-educational measure, including a list of suggestions to articulating the programs of socio-educational service with the schools. The study carries out a bibliographical and documentary research for the analysis of educational policies.

KeY words: Scholar education. Social education. Socio-educational measure. Teenagers in conflict with the law. School indiscipline.

\section{Introdução}

A educaçáo enquanto conceito de desenvolvimento integral do ser humano abrange todas as atividades que contribuem para o seu processo de humanização. Desde o período s primórdios da humanidade, o homem nas sociedades primitivas existentes no Brasil quando os portugueses aqui chegaram $^{1}$. Não havia outra divisão do trabalho senão aquela decorrente das atividades inerentes ao sexo e à idade: as mulheres cuidavam dos afazeres domésticos e da agricultura, colaboravam com a pesca e realizavam outras atividades artesanais, e os homens, caçavam, preparavam a terra para o plantio, fabricavam instrumentos de trabalho e vigiavam a segurança da aldeia.

Nesse contexto sociocultural, a criança se educava pela imitação, ajudando os pais em algumas atividades, cuidando dos irmáos menores, espantando pequenos roedores e pássaros das plantaçôes, além de realizar outras atividades correspondentes à sua idade. Não existia, por assim dizer, educação institucional e sistematizada, como ocorre atualmente. Também não se podia falar em direito ao lazer, à cultura e ao esporte visto que essas atividades eram integradas à educação da criança e relacionadas com o trabalho na comunidade. O trabalho, nessa perspectiva, é a matriz do ser 
social e todas as demais atividades - educação, cultura, esporte e lazer estabelecem, em relação a ele, uma dependência e uma autonomia relativa.

Anterior à sociedade capitalista, o trabalho não tinha como objetivo produzir mercadorias excedentes que possuíssem valor de troca; o avanço das forças produtivas tornou necessário que os homens fossem preparados para o mundo do trabalho e, por isso, parte da educaçáo passou a ser institucionalizada, deixando de ser realizada exclusivamente no seio da comunidade. A escola, criada na passagem da sociedade feudal para a sociedade capitalista possuía, como função social, ensinar às crianças e adolescentes os códigos da modernidade: leitura, escrita, cálculo, geografia, história, matemática, sendo essas ciências fundamentais para que o homem moderno pudesse avançar para formas de sociabilidade como as que temos no contexto atual do capitalismo, ainda que sejam cunhadas de contradiçóes.

Como já foi possível perceber, neste texto diferenciamos educação social, entendida como atividade de emancipação política, de educação escolar, vista como responsável pelo acesso ao conhecimento técnico e científico dos sujeitos. Quando falamos de educação social, estamos mencionando aquela formação que ocorre de maneira assistemática e não intencional, em todos os lugares da sociedade: na família, na comunidade, na igreja, nas atividades de lazer etc. Em um sentido amplo, são educadores: os pais, o padre, o pastor, os membros da família, os vizinhos, o telejornal, a novela, a internet, o desenho infantil, o rádio, enfim, tudo e todos que contribuem para o processo de formação política da criança e dos homens e mulheres da nossa sociedade. Essa educação é ampla e ocorre por toda a vida, de maneira permanente e não estritamente planejada, ou seja, nós não percebemos que estamos sendo educados, não há uma consciência filosófica que orienta essa educação, mas ela está acontecendo em todo o tempo e lugar. (SAVIANI, 2007)

As atividades de esporte e lazer estariam, dessa maneira, articuladas com essa formação integral do indivíduo de maneira assistemática, assim como a cultura, que em sua origem significa 'cultivar' e é entendida como um "[...] todo complexo que inclui conhecimentos, crenças, artes, moral, leis, costumes e todos os outros hábitos e aptidóes adquiridos pelo homem como membro da sociedade2." (TYLOR, 1920, p. 1) Poderíamos, inclusive, aproximar a ideia de educação social a uma sorte de educação 
cultural, visto que está relacionada com a sociedade em que a instituição está inserida.

E é assim que, no capitalismo, os modelos educacionais vigentes ensinarão os seus princípios. No sistema capitalista o homem prescinde de todo o seu tempo para o trabalho e quando não está trabalhando está se educando para trabalhar. Basta vermos, por exemplo, a gama de atividades imposta a crianças e adolescentes na contemporaneidade, o que torna necessário afirmar o direito de brincar das crianças. É consenso social que as atividades culturais, esportivas e de lazer conferem qualidade às relaçóes sociais estabelecidas na comunidade e na família, o que contradiz a lógica capitalista de que o homem não possua tempo livre e condiçóes econômicas para desenvolvê-las.

A compreensão de que o homem moderno precisa desses benefícios contribuiu para a institucionalização desses direitos. Ainda que a cultura e o lazer sejam formas assistemáticas e não intencionais de ensino da arte e da educação física, a mbas estão relacionadas intrinsecamente. Ocorre que, na escola a educação física e a arte possuem uma intencionalidade e, por isso, são ensinadas como ciência. Educar socialmente é também possibilitar que crianças e adolescentes tenham acesso a práticas esportivas, culturais e de lazer, dado que tais atividades educativas contribuem para o processo fundamental de emancipação humana. Esse processo é tão respeitável que a mais importante das normativas internacionais - a Declaração Universal dos Direitos Humanos (ORGANIZAÇĀO DAS NAÇÓES UNIDAS, 1948) - determinou que o repouso, o lazer e a educação fazem parte desses direitos. Os mesmos princípios foram posteriormente reproduzidos, acrescidos do direito à cultura, no documento que é considerado a carta de direitos humanos das crianças ${ }^{3}$ : a Declaração Universal dos Direitos da Criança (1959).

$\mathrm{Na}$ perspectiva de uma melhor diferenciação dos conceitos tornase imprescindível compreender que a educação que ocorre nas disciplinas escolares possui intencionalidade, objetivo, método, localizaçáo no espaço e no tempo histórico, enquanto a educação social é espontânea e está relacionada com o prazer de aprender, o lazer e a cultura da comunidade. Ainda que esses conceitos sejam próximos nas práticas escolares, a instituição possui apenas a responsabilidade de transmitir o conhecimento para, em conjunto com a educação social, viabilizar a emancipação po- 
lítica. Seria utopia acreditar que a escola, enquanto instituição burguesa, permeada de contradiçóes e limites, possibilitasse uma emancipação política desatrelada da educação social, que permeia a vida dos alunos de maneira integral. A educação ampla atrelada ao acesso à cultura, ao esporte e ao lazer, nesse sentido, é responsável pelo processo de humanização. Portanto, é coerente dizer que a sua ausência contribui para o processo de desumanização do homem.

A educação escolar é, dessa maneira, apenas uma parte da educação e possui como responsabilidade o ensino dos códigos da modernidade. Ainda que a educação integral e assistemática aconteça também na escola, a função social da instituição escolar é ensinar às crianças, adolescentes e jovens o conhecimento científico sistematizado pela humanidade. Por isso, podemos concluir que a educação integral de crianças e adolescentes é responsabilidade de toda a sociedade e também da escola, mas a responsabilidade por ensinar ler, escrever e contar não compete a toda a sociedade, mas essencialmente à escola ${ }^{4}$. Por isso, mesmo que a família seja parceira nessa tarefa, a escola é responsável pelo sucesso e pelo fracasso da criança no acesso ao conhecimento científico. Nesse sentido, se a função social da escola for substituída por outra, qual instituição fará a sua função, especialmente quando falamos de crianças e adolescentes que estudam em escolas públicas e são oriundos da classe trabalhadora.

Partindo dessa premissa, no próximo tópico buscaremos apresentar como as normativas nacionais cooperam para operacionalizar a intersetorialidade das políticas como forma de garantir náo apenas o acesso, mas também a permanência dos alunos nas escolas, contribuindo também para o enfrentamento da indisciplina e de todas as formas de violência praticadas e sofridas por crianças e adolescentes no âmbito da instituição e fora dela.

\section{Medidas de proteção e socioeducativas e sua relaçáo com a escola}

Ler, escrever, contar e dominar os códigos da modernidade é um direito humano, definido nas normativas internacionais e transposto para as normativas nacionais como direito fundamental de crianças e adoles- 
centes. Entretanto, se nas últimas décadas houve a universalização do ensino - coma garantia de direito à matrícula -, muito ainda falta para que consigamos universalizar a permanência na escola, visto que um a cada quatro alunos que inicia o Ensino Fundamental a abandona a escola antes de completar esse ciclo. $\mathrm{Na}$ lista dos países que possuem um maior Índice de Desenvolvimento Humano (IDH) o Brasil é o $4^{\circ}$ lugar com a maior taxa de abandono escolar (PNUD, 2013).

A análise indica uma realidade que os profissionais da área da educação e da área social identificam com certa facilidade nas escolas, municípios e comunidades em que atuam. Contudo, os problemas escolares são discutidos em duas situaçôes específicas: a primeira está relacionada aos resultados das avaliaçóes de larga escala, que evidenciam a não efetivação do processo de ensino aprendizagem; a segunda, à evasão escolar e à dificuldade de matrícula de alguns alunos nas escolas públicas, especialmente quando estes estão em cumprimento de medida socioeducativa. Não é necessário ser especialista em educação para concluir que o aluno que não aprende não possui interesse ou motivação para permanecer na escola, assim, temos que nos perguntar: $\mathrm{O}$ que leva os alunos da escola pública a não aprender? São os professores, exclusivamente, os responsáveis por essa não aprendizagem? Como os equipamentos sociais dos municípios e as famílias podem contribuir para que os direitos fundamentais de acesso e permanência se efetivem realmente?

A escola é uma instituição determinada socialmente, tudo o que acontece na sociedade é reproduzido na escola. A educação escolar realizase por meio dos homens, mulheres, crianças e adolescentes que estão inseridos na sociedade, isto é, professores, alunos, pedagogos, diretores e os demais profissionais que atuam na escola levam para essa instituição os problemas e os avanços sociais da comunidade em que a escola está inserida, de modo que podemos dizer que levam para ela a educação social que vivenciam nas comunidades em que vivem. Os avanços tecnológicos e da ciência, as mudanças culturais, corporais, políticas, econômicas e artísticas se materializam dentro dessa instituição, assim como a violência, a indisciplina, a não aceitação das normas e das regras de convívio, o consumismo, a banalização da vida, da ética e da moral, a busca pelo prazer efêmero, a relativização das relaçóes... enfim, na escola está representada a realidade 
social que vivemos, com as benesses das novas formas de sociabilidade e os prejuízos do capitalismo.

É importante evidenciar que escola e educação não transformam a ordem social vigente e, por isso, náo possuem a capacidade de mudar a realidade de toda a sociedade de forma coletiva, mas apenas individualmente. Ainda que no capitalismo a educaçáo escolar possibilite que no âmbito individual homens e mulheres alcancem melhores condiçôes econômicas e sociais, existem determinaçôes próprias do modo de produção capitalista que impossibilitam a viabilização de mudanças para o conjunto da sociedade. Isso não significa que devemos nos conformar com essa realidade, que se faz presente na luta de classes; cabe, sim, um alerta a todos que atuam em defesa dos direitos de crianças e adolescentes na direção de militem para que o direito à educaçáo, à cultura, ao esporte e ao lazer se materialize para o maior número possível de membros da nossa sociedade.

Quando se fala em direito a educaçáo, cultura, esporte e lazer prevalece a defesa do direito à educação escolar, os demais direitos surgem, quase sempre, como atividades ocupacionais que podem ou não se efetivar por meio de políticas públicas. No entanto, cabe mencionar que quanto maior for o acesso das crianças e adolescentes à cultura, ao esporte e ao lazer tanto maior será a qualidade da sua educaçấo e maior a possibilidade de sucesso na sua educação escolar, o que demonstra que os direitos são indivisíveis. É notório também que a viabilização de atividades culturais, esportivas e de lazer para os filhos da classe que não detém os meios de produção são atividades que, quase sempre, demandam parcos recursos humanos, materiais e financeiros, reproduzindo o entendimento de que para pobre qualquer coisa serve, ou ainda, de uma educação pobre para pobre, como já denunciou Alba Zaluar no livro Cidadãos não vão ao paraiso, de 1994.

Educação escolar de qualidade significa, dentre outras coisas, o cumprimento dos documentos normativos internos da instituição, vale dizer, a efetivação do Projeto Político-Pedagógico (PPP) e dos seus marcos situacionais, conceituais e operacionais, o cumprimento de uma Proposta Pedagógica Curricular (PPC) que sintetize o conhecimento historicamente produzido pela humanidade ${ }^{5}$ e a execuçáo de um Regimento Escolar que explicite a realidade da escola. 
O Regimento Escolar é o instrumento que organiza o funcionamento da instituição. Suas regras, normas e medidas são aplicáveis aos profissionais que atuam nesse espaço e também aos alunos nela inseridos. Assim, sempre que uma aula não foi dada (por comemoraçôes, atividades extracurriculares, atrasos e faltas de professores, mobilizaçóes etc.) o aluno deixou de ter acesso a um conteúdo que é pressuposto para a compreensão de outro. Da mesma forma, sempre que o aluno desrespeita as regras escolares, levando à escola objetos que são estranhos ao ambiente, faltou ou se atrasou, mais dificuldades enfrenta em relação ao processo de ensino-aprendizagem e mais próximo estará da reprovação, da evasão e do abandono escolar, o que evidencia que, se as dificuldades de aprendizagem alimentam a indisciplina, o seu contrário também é verdadeiro.

O Conselho Tutelar é o equipamento social que defende, irrestritamente, o melhor interesse da criança e do adolescente, conforme estabelecido no artigo 101 do Estatuto da Criança e do Adolescente (doravante, Estatuto). A Declaração Universal dos Direitos da Criança estabelece em seu princípio VII que "O interesse superior da criança deverá ser o interesse daqueles que têm a responsabilidade por sua educação e orientação; tal responsabilidade incumbe, em primeira instância, a seus pais" (ORGANIZAÇÃO DAS NAÇŌES UNIDAS, 1959, s/p) e a instituição responsável por eles, durante determinado período. Garantir o melhor interesse da criança e do adolescente é defender os princípios da proteção integral, tendo em vista a sua condição peculiar de desenvolvimento, o que nem sempre significa atender ao interesse expresso pela criança e pelo adolescente.

A ausência de reflexôes sobre a importância do acesso à educação de qualidade para a classe social desfavorecida tem permeado o embate entre os profissionais da área social e da área da educação. A universalização do acesso à escola pública foi uma conquista dos educadores brasileiros. Esperava-se, então, que essa universalização significasse o acesso ao conhecimento sistematizado pela humanidade; entretanto, passadas três décadas dessa conquista, observamos que a instituição escolar tem sido ideologicamente destituída da sua função de ensinar, sendo solicitado a ela que apenas cuide dos alunos, mantendo-os fora das ruas pelo período de quatro horas.

Para melhor elucidar e tornar mais didática essa situação convém discorrer sobre um caso bastante divulgado na mídia do estado do Paraná, no 
qual a escola, depois de verificar um número aproximado de 500 atrasos diários, resolveu tomar providências em relação ao problema. Depois de realizar várias reuniôes com pais de alunos alertando sobre os danos que os atrasos escolares geram ao aluno, a escola avisou que tomaria medidas para coibir o problema, que consistia no fato de que os alunos que chegassem atrasados seriam impedidos de entrar na instituição. Além de reunióes, a decisão foi oficiada aos pais por meio de bilhetes com a explicaçáo de que os alunos que atrasavam diariamente eram recolhidos no pátio da escola, o que atrapalhava os alunos e professores que estavam em sala de aula ${ }^{6}$ (O DIÁRIO, 2011a). No dia em que se iniciou a aplicação da medida, os profissionais da escola se mantiveram nos portóes informando aos alunos atrasados que deveriam voltar para suas casas, permitindo-se a entrada apenas dos que possuíam atestado médico como justificativa. No primeiro dia voltaram para casa, aproximadamente, 100 alunos; no segundo dia foram dez os que retornaram. A medida estava possibilitando que mais de 400 alunos tivessem acesso ao que é a função social da escola, qual seja: ensinar. Entretanto, insatisfeita com a decisão, uma das famílias procurou o Conselho Tutelar alegando que o direito de sua filha de entrar na escola estava sendo violado. Assim, no terceiro dia um Conselheiro Tutelar foi à imprensa defender que os alunos de escolas públicas possuem o direito de se atrasar e entrar na escola, independentemente do motivo e da quantidade de vezes que isso ocorra. $(\mathrm{O}$ DIÁRIO, 2011b; GAZETA MARINGÁ, 2011)

Sabemos que um atraso pode acontecer como uma exceção, mas no caso das escolas públicas, é conveniente mencionar que não o são, mas constituem uma regra cultural. A exceção não significaria a reprovação, pois é necessário que ocorram muitos atrasos para que um aluno reprove. Para as exceçóes existem justificativas, como o atestado médico. Os demais casos de atraso (dormiu até mais tarde, trânsito, esteve em outros locais antes de vir para a escola, ficou conversando com amigos na praça etc.), que se repetem regularmente, não são exceçôes, isto é, ocorrem com regularidade. Ora, quando a escola permite que o aluno entre em qualquer horário, os atrasos não são notados, portanto, ele está em iminente risco social e desprotegido, já que os pais pensam que ele está na escola. Quando o número de atrasos é pequeno a equipe pedagógica da escola costuma avisá-los dessas ocorrências; entretanto, o aumento nesse número impede que essa ação seja realizada. Além disso, muitos 
pais estão trabalhando e não conseguem atender ao telefone, o que atrapalha a comunicação e, mesmo que os responsáveis sejam notificados do atraso, a repetição dele significa que o melhor interesse da criança e do adolescente não está sendo garantido. Convém observar que o ocorrido na escola mencionada contribuiu para que os alunos realizassem reunióes com a direçáo exigindo que o mesmo procedimento fosse tomado em relaçáo aos professores que atrasavam. De maneira geral, a medida só havia trazido benefícios para o processo de ensino-aprendizagem, já que a solicitação foi acatada pela direção.

$\mathrm{O}$ direito a um adequado processo de ensino-aprendizagem representa o melhor interesse do aluno e tudo o que concorrer para que isso náo aconteça vai contra esse princípio consignado na Declaração dos Direitos da Criança e deve ser motivo de intervençáo dos equipamentos que atuam na defesa desses direitos. Nesse sentido, até mesmo a ausência ou atraso de professores e a falta de merenda, transporte ou material didático adequado - conforme estabelecido no inciso VII do artigo 54 do ECA - precisam ser averiguados e denunciados, cabendo aos violadores medidas adequadas de responsabilização. Da mesma maneira, medidas de proteção devem ser aplicadas sempre que os direitos de crianças e adolescentes forem ameaçados ou violados por falta, omissáo e abuso dos pais ou responsáveis e do Estado, ou ainda quando crianças ou adolescentes se coloquem em situação de risco (artigo 98, ECA), como são os casos de atrasos, indisciplina e violência física ou psicológica. Tais medidas devem ser aplicadas pelo próprio Conselho Tutelar, que deve requisitar que crianças, adolescentes, pais e responsáveis recebam atendimento na área da saúde e assistência social. A requisição de tais serviços passa pelo acompanhamento psicológico, psiquiátrico e médico em regime hospitalar e ambulatorial, inclusão em programa comunitário ou oficial de auxílio à família, tratamento para situaçóes de uso e abuso de substâncias psicoativas, orientação, apoio e acompanhamento temporários, conforme determina o artigo 101 da mesma Lei. (BRASIL, 1990)

No caso de situaçóes envolvendo violência física ou contra o patrimônio a Lei no 12.594/2012, que instituiu o Sistema Nacional de Atendimento Socioeducativo (SINASE), explicita que as medidas socioeducativas têm como objetivo responsabilizar o adolescente, incentivando a reparação do ato praticado e a desaprovaçáo da conduta infracional 
(BRASIL, 2012). As situações de atos infracionais cometidos no ambiente escolar por adolescentes devem ser passíveis de uma medida pedagógica como ressarcimento do dano, em casos materiais e/ou resolução pacífica de conflitos por danos pessoais ${ }^{7}$. Entretanto, convém mencionar que a não possibilidade de acordo entre as partes lesadas significa que medidas mais rigorosas devem ser tomadas. Nesses casos, a Polícia Militar deve ser comunicada e o boletim de ocorrência registrado, náo sendo adequado nem mesmo educativo que se dê a impressão de que os adolescentes podem violar as normas sociais, destruindo patrimônio público, promovendo violência física e psicológica contra outros alunos e membros da equipe, sem uma adequada sanção para que não se repercuta o discurso de que 'não dá nada'.

O princípio de que a educação escolar é direito fundamental se estende aos adolescentes que cometeram atos infracionais e que foram responsabilizados por uma medida socioeducativa. Geralmente, situaçóes de violação das normas escolares são sancionadas com medidas de advertência (Artigo 112, Inciso I), reparação de danos (Artigo 112, Inciso II) ou medida em meio aberto - Prestação de Serviço à Comunidade (Artigo 112, Inciso III) ou Liberdade Assistida (Artigo 112, Inciso IV). Nessas situaçóes, o adolescente continua frequentando a escola, mas é correto que a instituição mantenha contato com o Programa que executa a medida socioeducativa em meio aberto no município de maneira a informar como está o comportamento do aluno ${ }^{8}$. Essas informaçôes servirão de subsídio para que o Programa elabore o relatório ao Judiciário sugerindo o desligamento ou a manutenção da medida socioeducativa. Obviamente que se o adolescente possui ciência dessa relação entre a escola e o Programa isso influenciará positivamente no seu comportamento escolar. Conforme determina o Estatuto no artigo 119, Inciso II, o orientador da medida socioeducativa no município deve não apenas matricular o adolescente, mas, juntamente com a família, acompanhar o seu aproveitamento escolar. Sabemos que o acompanhamento no ato da matrícula nem sempre é cumprido pelos programas de medidas em meio aberto, por isso, as escolas se sentem vulneráveis por acolherem, novamente, o aluno que apresentou um comportamento indevido na instituição, buscando, sempre que possível, negar a vaga da matrícula, o que é equivocado. Nesses casos, a instituiçáo deve entrar em contato com o profissional de referência no programa de medidas em meio aberto e solicitar a sua presença na escola, para estabe- 
lecer um diálogo e realizar o efetivo acompanhamento escolar do aluno. Ainda que a medida aplicada seja a privação ou a restrição de liberdade (Artigo 112, Inciso VI ou V), uma vez desinternado o adolescente deverá ser imediatamente matriculado na escola para dar continuidade aos estudos que realizou durante a internação.

Sabemos que os profissionais da educação se deparam, cotidianamente, com crianças e adolescentes que apresentam um comportamento que se diferencia dos demais em relação à sua idade, cultura e comportamento, o que tem relação com a sua educação social. No entanto, existem situaçôes que evidenciam que algo na sua família ou comunidade está incomodando. Ocorre que situaçóes mais graves envolvendo outras crianças e adolescentes ocupam a atenção e o tempo dos profissionais da escola; frente às demandas existentes ambos os profissionais da educação ou da área social optam por resolver aquelas que são mais emergentes. Por desconhecer o papel da rede de proteção, os membros da escola desconsideram situaçôes de violência que acontecem no interior da família ou na comunidade, apesar de terem conhecimento delas. Tais problemas, quase sempre, constituem sintomas que promovem um comportamento indisciplinado que precede o comportamento infrator.

Muitas vezes, o aluno tem medo de denunciar uma violência que está sofrendo. Alunos que sofrem abuso sexual, por exemplo, podem ser agressivos, agitados, indisciplinados ou o contrário: ausentes, sonolentos, pouco participativos ou, ainda, apresentar medo excessivo. Importante mencionar que apenas um dos sintomas não significa que está ocorrendo abuso sexual, mas é importante ficar alerta com a comorbidade de dois ou mais sintomas. Sono, por exemplo, é um sintoma recorrente na escola. O aluno que dorme regularmente em sala de aula pode estar denunciando o uso regular de cannabis sativa (maconha), violência doméstica, ou ainda, que ele permanece até de madrugada acordado na internet, por exemplo. Por isso, mesmo quando a escola contorna essas situaçôes, não é normal que um aluno permaneça dormindo em sala de aula. Por isso, após informar os pais, se o caso persistir, a rede de proteção precisa se acionada para identificar o que está contribuindo para que o aluno o apresente. Em algumas situaçóes o aconselhamento dos pais sobre os horários irá resolver, em outras situaçóes é necessário o atendimento na área da saúde ou na rede socioassistencial. 
Importante mencionar que o adolescente usuário de maconha não será incomodativo enquanto dorme, mas se tornará quando o uso for abusivo ou estiver traficando. Nessas situaçóes, a Polícia Militar será comunicada, mas é incoerente que, na maioria dos casos, nenhuma medida de proteção anterior tenha sido tomada para ajudar o adolescente ou a família, visto que a educação social possui relação com a educação escolar.

\section{A rede de proteçáo no apoio à educação escolar e a inserçáo escolar do adolescente oriundo do sistema socioeducativo}

Muito se tem dito, ideologicamente, que o aluno da atualidade possui outros interesses e que a escola pública não consegue mais atendê-los, tendo em vista o domínio instrumental das mídias tecnológicas. Entretanto, se o conhecimento escolar não é fundamental, para que se possa fazer parte das redes sociais, informação não significa conhecimento. É incoerente que as classes hegemônicas não abram mão de que seus filhos tenham o melhor conhecimento científico e acadêmico que se possa comprar na escola burguesa enquanto defendem, de maneira ideologizada, que para os filhos da classe trabalhadora apenas o acesso à informação é suficiente.

A defesa desses pressupostos contribui para diminuir o compromisso dos profissionais da educação, da família, dos alunos, dos políticos e da rede socioassistencial com o acesso ao conhecimento sistematizado pela humanidade. Se perguntássemos os motivos pelos quais a classe média ou dominante escolhe determinada escola para seus filhos estudarem, dentre eles estariam listados: rígido cumprimento de horário e uniforme, segurança, náo utilizaçáo de celulares na escola e, principalmente, o cumprimento do currículo - condição primeira para que esse aluno possa ser aprovado no vestibular e, consequentemente, ter acesso a uma melhor vaga no mercado de trabalho.

Nesse sentido, questionamos: Por quais motivos os conselhos de direitos e membros da rede de proteçáo passaram a defender que o mais importante é que o aluno esteja protegido no ambiente escolar? O discurso da escola como instituição de defesa e proteção de crianças e adolescen- 
tes é regularmente apresentado nos textos sobre o Sistema de Garantia de Direitos e isso é, em parte, verdadeiro, mas também ideológico. Essa não pode ser a maior defesa em relação à escola pública, pois subjetivamente implica dizer que para esses alunos basta o espaço protetivo, o que destitui a escola de sua função social.

A luta pela ampliação dos espaços coletivos públicos de lazer, cultura e esporte para as crianças e adolescentes filhos da classe trabalhadora é uma necessidade permanente. A compreensão de que a escola deve responder a todas as demandas sociais, contribui para o enfraquecimento dessas políticas e dá a ela outras atribuiçóes que não deveriam estar sob sua responsabilidade, visto que os profissionais que lá estão não possuem condiçôes adequadas de realizá-las. Se a escola possui como função apenas o cuidar, e não o ensinar, o compromisso do direito à educação seria cumprido mesmo se após dez anos de frequência o aluno não estivesse plenamente alfabetizado. Transmitir o conhecimento é a função social da escola, enquanto o cuidar é da escola, da família, da sociedade, dos equipamentos socioassistenciais e de saúde, portanto, uma responsabilidade social. Sempre que a escola é chamada a cuidar, outra instituição deve ser convocada a assumir essa responsabilidade junto com ela.

O Plano Nacional de Educação em Direitos Humanos estabelece que os direitos humanos são universais, indivisíveis e interdependentes; por isso, todas as políticas devem considerá-los no compromisso da universalização do ensino e da educação de todas as crianças e adolescentes, já que a educação escolar "[... e é compreendida como um direito em si mesmo e um meio indispensável para o acesso a outros direitos." (BRASIL, 2007, p. 25). Por essa razão, o compromisso com a educação escolar está diretamente relacionado com a escola, mas é também compromisso de toda a rede de proteção existente no município.

Manifestaçôes recorrentes sobre a dificuldade que o sistema socioeducativo de privação e restrição de liberdade e o meio aberto têm encontrado para viabilizar a matrícula dos adolescentes, durante ou após o cumprimento da medida, têm sido frequentes. É comum nas formaçóes e palestras o debate sobre como a escola regular tem dificultado, de maneira dissimulada, a matrícula e o acesso desses adolescentes. Entretanto, apesar das reclamaçóes os profissionais que atuam no sistema socioeducativo pouco têm feito, efetivamente, para buscar uma aproximação com 
a instituição escolar e minimizar a visão estigmatizada que tais profissionais possuem.

Além disso, muitas vezes o modelo escolar das unidades de internação tem se diferenciado do modelo adotado nas escolas da rede, especialmente porque os professores dessas unidades têm realizado um ensino maternal, com características assistencialistas e de escuta ativa, deixando de lado o currículo escolar e realizando outras atividades de promoção do bem-estar biopsicossocial. Essa situação tem sido caracterizada como uma tendência neoescolanovista na educaçáo, pois as atividades que fomentam apresentam-se como um desvio que, apesar de promover bem-estar emocional momentâneo para o adolescente, em nada contribuem para seu avanço no processo educacional, muito mais aprofundam o fosso existente entre a inserção e a permanência escolar desses jovens depois do desligamento da medida socioeducativa.

Tendo em vista esse contexto, apresentamos algumas sugestôes para viabilizar uma melhor relação entre o adolescente e a escola da rede de proteção durante o cumprimento da medida de semiliberdade ou internação:

a) realizar reunióes com as famílias para tratar do percurso escolar do adolescente durante o cumprimento da medida, responsabilizandoas por esse acompanhamento;

b) contatar a escola de origem do adolescente mantendo o pedagogo informado sobre o cumprimento da medida socioeducativa;

c) convidar o pedagogo escolar para participar de atividades de estudo de caso e elaboração do Plano Individualizado de Atendimento (PIA);

d) realizar visitas na escola de origem, sempre que possível em conjunto com o adolescente;

e) promover círculos restaurativos entre família, adolescente e profissionais da escola de maneira a estabelecer um vínculo que se proporcione melhor acolhimento no período posterior ao cumprimento da medida;

f) preparar o desligamento do adolescente da internação ou a sua inserção quando em medida de semiliberdade, tomando como prioritário o acesso à escola; 
g) garantir que o currículo escolar de cada disciplina seja trabalhado em sala de aula de maneira similar ao que ocorre nas escolas da rede, como forma de garantir que o adolescente consiga se adaptar no seu retorno ao ambiente escolar regular;

h) organizar o material escolar do adolescente, preparando-o para o retorno à escola depois do desligamento; e

i) acompanhar, sempre que possível, o adolescente e sua família no primeiro contato com a escola na rede de proteçáo.

As sugestóes apresentadas foram elaboradas a partir de reunióes realizadas com pedagogos e professores que atuam no sistema socioeducativo em diferentes estados da federação e visam minimizar a lacuna existente com a escola de origem no período que o adolescente cumpre a medida socioeducativa de internação e semiliberdade.

\section{Consideraçóes Finais}

$\mathrm{O}$ artigo apresentou, inicialmente, os princípios dos direitos à educação, à cultura, ao esporte e ao lazer; posteriormente, evidenciou a toricamente produzidos pela humanidade, de maneira a refletir sobre os motivos que têm contribuído para que os adolescentes evadam das escolas, e debateu o papel dos equipamentos da rede de proteção, especialmente do Conselho Tutelar. Finalmente, tratou da inserçáo escolar de adolescentes oriundos do sistema socioeducativo durante o cumprimento de semiliberdade ou posteriormente ao desligamento da internação, apresentando indicaçôes para mediar as relaçôes entre equipamentos sociais, família, adolescente e a escola.

$\mathrm{O}$ artigo apresentou reflexões sobre os fundamentos da educação social como forma de evidenciar a função da educaçáo escolar, problematizando questóes como atrasos, violências domésticas e comunitárias, dentre outras, que no conjunto têm contribuído para que a escola e seus profissionais não consigam realizar a sua função social, que é a transmissão do conhecimento socialmente produzido pela humanidade. Além disso, busca desvelar as confusóes ideológicas sobre o papel de cuidar e educar da escola. 


\section{Finalmente, apresentou sugestóes para minimizar os problemas que contri- buem para que os adolescentes em conflito com a lei não consigam realizar a inserção escolar, posterior ao cumprimento da medida internação e durante a permanência na semiliberdade e nas medidas em meio aberto.}

\section{Notas}

1 Neste artigo, quando falamos de homem/homens estamos nos referindo aos homens e mulheres que pertencem ao gênero humano, constituído necessária e concretamente por homens e mulheres. Evitamos a utilização de o/a, os/as para deixar o texto fluido.

2 Culture or Civilization, taken in its wide ethnographic sense, is that complex whole which includes knowledge, belief, art, morals, law, custom, and any other capabilities e habits acquired by man as a member of society. (Traduçáo livre dos autores, 2013)

3 A Declaração Universal dos Direitos Humanos considera crianças todos aqueles que possuem idade inferior a 18 anos.

4 Convém mencionar que a prática de escolarizar em casa vem tomando corpo. Homeschooling, Unschooling, Home Education, Ensino Doméstico, Ensino Domiciliar são termos utilizados para explicar o fato de que algumas famílias têm defendido se responsabilizar por ensinar em casa ao invés de enviar seus filhos para uma escola com a justificativa de que valores, costumes, hábitos, moral e crenças fazem parte da educação dos filhos. No Brasil, a Associação Nacional de Educação Domiciliar (ANED) luta pela autonomia educacional da família realizando conferências e audiências públicas, defendendo o tema na mídia e buscando regulamentação legislativa. O tema precisa de maior estudo, mas já possui mais de 2.500 famílias adeptas do modelo. (ANED, 2017; BOTO, 2018)

5 O PPP e a PPC definem quais fundamentos filosóficos e teóricos orientam a escola e também o que deverá ser ensinado em cada série, bimestre e disciplina curricular.

6 Convém mencionar que a maioria das escolas públicas nấo possuem espaços e auditórios para que os alunos fiquem reunidos sem atrapalhar as aulas que ocorrem dentro das salas de aula. Geralmente, os alunos ficam no pátio coberto central que dá acesso às salas. A insuficiência de profissionais para acompanhar e coibir a circulação produz transtornos, já que aqueles que chegaram atrasados chamam a atenção dos demais alunos que estâo nas salas, o que aumenta o problema.

7 Ao ato infracional praticado por criança corresponderão as medidas de proteçấo previstas no artigo 101 do Estatuto da Criança e do Adolescente, e serão aplicadas pelo Conselho Tutelar. (BRASIL, 1990)

8 Geralmente, nos municípios de pequeno porte esses programas encontram-se atrelados ao Centro de Referência da Assistência Social (CRAS) e nos municípios de médio e grande porte ao Centro de Referência Especializado da Assistência Social (CREAS).

\section{Referências}

ANED. Associação Nacional de Educação Domiciliar. Pela autonomia educacional da familia. Disponível em: <https://www.aned.org.br/>. Acesso em: 16 jan. 2019. (2019). 
BOTO, Carlota. "Homeschooling": a prática de educar em casa. In: Jornal da USP. Publicado em: 16 mar. 2018. Acesso em: 16 jan. 2019. Disponível em: <https://jornal. usp.br/artigos/homeschooling-a-pratica-de-educar-em-casa/>. (2018).

BRASIL. Estatuto da criança e do adolescente: Lei no 8.069, de 13/jul/1990. Disponível em: <http://www.planalto.gov.br/ccivil_03/leis/18069.htm>. Acesso em: 15/mai./2011.

BRASIL. Lei 12.594 de 18 de janeiro de 2012. Acesso em: 06/fev./2012. Disponível em: <http://www.planalto.gov.br/ccivil_03/_ato2011-2014/2012/lei/l12594.htm>.

BRASIL. Lei de Diretrizes e Bases da Educação Nacional. Lei no 9.394, de 20/dez./1996. Disponível em: <http://www.planalto.gov.br/ccivil_03/leis/19394.htm>. Acesso em: 15/ mai./2011.

BRASIL. Plano Nacional de Educação em Direitos Humanos: educação básica, ensino superior, educação não-formal, educação dos profissionais do sistema de justiça e segurança, educação e mídia. Brasília: Secretaria Especial dos Direitos Humanos, Ministério da Educaçáo, Ministério da Justiça, UNESCO, 2007.

GAZETA MARINGÁ. Conselho Tutelar é chamado para garantir entrada de alunos em colégio de Maringá. Publicado em: 23 maio 2011. Disponível em: <https://www. gazetadopovo.com.br/vida-e-cidadania/maringa/conselho-tutelar-e-chamado-paragarantir-entrada-de-alunos-em-colegio-de-maringa-4rtuucd8ixwqvjrfgwdmddv0u/>. (2011). Maringá. Publicado em: 20 nov. 2011. Disponível em: <http://maringa.odiario.com/ maringa/noticia/420372/alunos-atrasados-sao-proibidos-de-entrar-no-instituto-deeducacao/>. Acesso em: 16 jan. 2019. (2011a).

O DIÁRIO. Na maioria dos casos são os mesmos que chegam atrasados diz diretora do Instituto de Educação. Publicado em: 23 maio 2011. Disponível em: <https://maringa. odiario.com/maringa/2011/05/na-maioria-dos-casos-sao-os-mesmos-alunos-quechegam-atrasados-diz-diretora-do-instituto-de-educacao-de-maringa/421610/>. Acesso em: 16 jan. 2019. (2011b).

ORGANIZAÇÃO DAS NAÇÓES UNIDAS (ONU). Declaração dos direitos da criança. Proclamada pela Resolução da Assembleia Geral 1386 (XIV), 20/nov./1959.

ORGANIZAÇÃO DAS NAÇŌES UNIDAS (ONU). Declaração Universal dos Direitos Humanos. Adotada e proclamada pela Resoluçáo 217A da Assembleia Geral das Naçóes Unidas. 10/dez./1948.

PNUD. Relatório do desenvolvimento humano 2013: a ascensão do sul: progresso humano num mundo diversificado. Portugal: Instituto Camóes, 2013. Acesso em 16/ mai./2013. Disponível em: <http://www.pnud.org.br/arquivos/rdh-2013.pdf>. 
SAVIANI, Dermeval. Educação: do senso comum à consciência filosófica. 17. ed. rev. Campinas, SP: Autores Associados, 2007. (Coleção educação contemporânea).

TYLOR, Edward B. Primitive culture: researches into the development of mythology, philosophy, religion language, art, and custom. 6. ed. London: John Murray, 1920. vol. I ZALUAR, Alba. Cidadãos não vão ao paraíso: juventude e política social. Campinas, SP: Unicamp, 1994.

Recebido em I3 fev. 20I9 / Aprovado em I5 mar. 2019 Para referenciar este texto:

ZANELLA, M. N.; LARA. A. M. B.; CABRITO, B. G. Educação social e escolar e o direito à educação na medida socioeducativa. EccoS - Revista Científica, São Paulo, n. 48, p. I55-I73. jan./mar. 2019. Disponível em: <https://doi.org/10.5585/EccoS. n48.II43I $>$. 
